\title{
ITS2 variability of Biomphalaria (Mollusca, Planorbidae) species from the Paranapanema Valley (São Paulo State, Brazil): Diversity patterns, population structure, and phylogenetic relationships
}

\author{
Roseli Tuan and Priscila dos Santos \\ Laboratório de Bioquímica e Biologia Molecular, Superintendência de Controle de Endemias, \\ Secretaria da Saúde do Estado de São Paulo, São Paulo, SP, Brazil.
}

\begin{abstract}
The ribosomal DNA internal transcribed spacer 2 (ITS2) has been shown to be a useful genetic marker for species identification and phylogenetic reconstruction in the genus of freshwater snails Biomphalaria (Preston 1910). Additionally, ITS2 studies in Biomphalaria have uncovered significant intra-specific genetic variability suggesting the presence of cryptic species complexes. We obtained ITS2 sequences for the Biomphalaria species B. glabrata, $B$. tenagophila, B. occidentalis and B. peregrina from the Paranapanema Valley (São Paulo State, Brazil) and compared them with a comprehensive set of published Biomphalaria ITS2 sequences using Bayesian inference of phylogeny. Analysis of the resulting trees showed that the newly obtained B. glabrata sequences did not cluster with those from other Brazilian localities and that sub-structuring occurred among Brazilian B. tenagophila populations. Moreover, although ITS2 sequences seem to indicate clear genetic differentiation within both B. glabrata and $B$. tenagophila, evidence in support of the occurrence of cryptic species is more compelling for the latter. We discuss the significance and implications of the detected patterns of ITS2 variability for taxonomic studies in Biomphalaria.
\end{abstract}

Key words: Bayesian inference, Biomphalaria, DNA sequences, internal transcribed spacer 2 (ITS2), ribosomal DNA.

Received: December 13, 2005; Accepted: August 9, 2006.

Species of planorbid snails belonging to the genus Biomphalaria, which includes the vectors of the blood fluke Schistosoma mansoni, have recently received increasingly attention in molecular systematic and phylogeography studies (Campbell et al., 2000; Vidigal et al., 2000, 2004; DeJong et al., 2001; Mavárez et al., 2002; Pointier et al., 2005). These studies have largely supported the pivotal body of work on the taxonomy of Neotropical Biomphalaria carried out by malacologist Lobato Paraense (Paraense, 2001) and, additionally, uncovered interesting patterns of intraspecific variability (Mavárez et al., 2002; Vidigal et al., 2004).

Among the genetic markers used so far in studies on Biomphalaria, the nuclear ribosomal DNA (rDNA) internal transcribed spacers (ITS) have been shown to be particularly useful for species identification and phylogenetic reconstruction (Campbell et al., 2000; Vidigal et al., 2000; Pointier et al., 2005). Furthermore, ITS sequence studies have revealed and/or confirmed sub-structuring within widely distributed species such as B. glabrata and $B$.

Send correspondence to Roseli Tuan. Superintendência de Controle de Endemias, Rua Paula Souza 166, $5^{\circ}$ andar 01027-000 São Paulo, SP, Brazil. E-mail: rtuan@sucen.sp.gov.br. tenagophila (Mavárez et al., 2002; Vidigal et al., 2004), adding to the body of evidence indicating that these nominal taxa may constitute complexes of cryptic species (Woodruff and Mulvey, 1997; Spatz et al., 1999). In these circumstances, the investigation of genetic variability patterns across the range of distribution of these species takes a prominent role in helping to elucidate how many independently evolving entities there are and which geographical areas they occupy.

In this study, we obtained nuclear ribosomal DNA (rDNA) internal transcribed spacer 2 (ITS2) sequences from B. glabrata, B. tenagophila, B. occidentalis and B. peregrina specimens collected in the Paranapanema Valley region (São Paulo State, Brazil). The newly obtained sequences were compared to all other ITS2 sequences published to date for the same species. In doing so, we addressed the following issues: polymorphism and divergence patterns, phylogenetic relationships, and the possible occurrence of species complexes in Biomphalaria.

We collected 16 Biomphalaria snails (Table 1) along the banks of different streams of the Paranapanema River in Ourinhos (lat -22.98, lon -49.87) and Ipauçu (lat -23.05, lon -49.62) and extracted total genomic DNA from the foot tissue of individual specimens using DNeasy Tissue Kits 
Table 1 - Biomphalaria rDNA ITS2 sequences used in the study.

\begin{tabular}{|c|c|c|}
\hline Species and localities where collected & Sequence code & ITS2 GenBank accession numbers \\
\hline \multicolumn{3}{|l|}{ B. glabrata } \\
\hline Ourinhos (SP), Brazil & BglOur 1 BglOur 2 BglOur 3 & DQ143952 DQ143953 DQ143954 \\
\hline Esteio (RS), Brazil & BglEst 1 BglEst 2 & $\mathrm{AF} 198660^{l} \mathrm{AF} 198661^{l}$ \\
\hline Belo Horizonte (mg), Brazil & $B g l B H$ & $\mathrm{AF} 449582^{3}$ \\
\hline Salvador (BA), Brazil & BglSal 1 BglSal 2 & AY030376 ${ }^{2} \mathrm{AF} 449581^{3}$ \\
\hline Belém (PA), Brazil & BglBel & $\mathrm{AF} 198659^{l}$ \\
\hline Aragua, Venezuela & BglAra & AY030377² \\
\hline Calicanto, Venezuela & $\mathrm{BglCal}$ & AF449589 ${ }^{3}$ \\
\hline Caripe, Venezuela & BglCar & AF449583 ${ }^{3}$ \\
\hline Chuao, Venezuela & BglChu & AF449588 \\
\hline Los Naranjos, Venezuela & BglLN 1 BglLN 2 & AF449584 ${ }^{3}$ AF449585 $5^{3}$ \\
\hline Portuguesa, Venezuela & BglPor & $\mathrm{AF} 198662^{l}$ \\
\hline Punta Cabito, Venezuela & $B g l P C$ & $\mathrm{AF} 449591^{3}$ \\
\hline Tres Lances, Venezuela & BglTL 1 BglTL 2 & $\mathrm{AF} 449586^{3} \mathrm{AF} 449587^{3}$ \\
\hline Zuata, Venezuela & BglZua & $\mathrm{AF} 449590^{3}$ \\
\hline Pierrot, Saint-Lucia & BglPie & AF449596 $6^{3}$ \\
\hline Maupéou, Martinique & BglMau & AF449593 ${ }^{3}$ \\
\hline Grand Camp, Guadeloupe & $B g l G C$ & $\mathrm{AF} 449595^{3}$ \\
\hline Vallet, Guadeloupe & BglVal & $\mathrm{AF} 449592^{3}$ \\
\hline Vieux-Fort, Guadeloupe & $B g l V F$ & AF449594 ${ }^{3}$ \\
\hline Rio Grande Town, Puerto Rico & $B g l R G$ & AY030375 \\
\hline Jarabacoa, Dominican Republic & BglJar & AY030374 ${ }^{2}$ \\
\hline \multicolumn{3}{|l|}{ B. tenagophila } \\
\hline Ourinhos (SP), Brazil & BttOur 1-2 BttOur 3 BttOur 4 BttOur 5 & DQ143955 DQ143956 DQ143957 DQ143958 \\
\hline Ipauçu (SP), Brazil & BttIpa $1-4$ & DQ143959 \\
\hline Imbé (RS), Brazil & BttImb & $\mathrm{AF} 198655^{l}$ \\
\hline Taim (RS), Brazil & BttTai & AY $631860^{5}$ \\
\hline Contagem (MG), Brazil & BttCon & AF449614 ${ }^{3}$ \\
\hline Vespasiano (MG), Brazil & BttVes & $\mathrm{AF} 198654^{l}$ \\
\hline Formosa (GO), Brazil & BttFor 1 BttFor 2 & AF198656 ${ }^{1}$ AY030388 ${ }^{2}$ \\
\hline Itamaraju (BA), Brazil & BttIta & AY $631859^{5}$ \\
\hline Asunción, Paraguay & BttAsu & AY030387² \\
\hline Araza, Argentina & BttAra & AY425746 ${ }^{4}$ \\
\hline Bonpland, Argentina & BttBon & AY $425745^{4}$ \\
\hline Kinshasa, Democratic Republic of Congo & BttKin & AY $631861^{5}$ \\
\hline \multicolumn{3}{|l|}{ B.t.guaibensis } \\
\hline Esteio (RS), Brazil & BtgEst & AY $425749^{4}$ \\
\hline Guaíba (RS), Brazil & BtgGua & AY $425750^{4}$ \\
\hline Termas, Uruguay & BtgTer & AY425751 ${ }^{4}$ \\
\hline \multicolumn{3}{|l|}{ B. occidentalis } \\
\hline Ourinhos (SP), Brazil & BocOur 1-2 & DQ143960 \\
\hline Caceres (MG), Brazil & $\mathrm{BocCac}$ & $\mathrm{AY} 030389^{2}$ \\
\hline Capetinga (MG), Brazil & BocCap & $\mathrm{AF} 198658^{l}$ \\
\hline Campo Grande (MS), Brazil & $B o c C G$ & $\mathrm{AF} 198657^{1}$ \\
\hline Triângulo, Argentina & BocTri & AY $425748^{4}$ \\
\hline Villa Chica, Argentina & BocVC & $\mathrm{AY} 425747^{4}$ \\
\hline \multicolumn{3}{|l|}{ B. peregrina } \\
\hline Ourinhos (SP), Brazil & BpeOur 1 BpeOur 2 & DQ143961 DQ143962 \\
\hline Taim (RS), Brazil & BpeTai & $\mathrm{AF} 198677^{1}$ \\
\hline Alfenas (MG), Brazil & BpeAlf & $\mathrm{AF} 198676^{l}$ \\
\hline Bom Jesus da Penha (MG), Brazil & BpeBJ & $\mathrm{AF} 198678^{l}$ \\
\hline Nova Lima (MG), Brazil & BpeNL & $\mathrm{AY} 030401^{2}$ \\
\hline San Antonio, Uruguay & BpeSA & AY030400² \\
\hline
\end{tabular}

${ }^{1}$ Vidigal et al. (2000); ${ }^{2}$ DeJong et al. (2001); ${ }^{3}$ Mavárez et al. (2002); ${ }^{4}$ Vidigal et al. (2004); ${ }^{5}$ Pointier et al. (2005).

Acronyms for Brazilian states shown between parentheses: $\mathrm{BA}=$ Bahia; $\mathrm{GO}=$ Goiás; $\mathrm{mg}=$ Minas Gerais; $\mathrm{PA}=\mathrm{Pará}$; $\mathrm{RS}=\mathrm{Rio} \mathrm{Grande}$ do $\mathrm{Sul}$; and $\mathrm{SP}=$ São Paulo. 
(Qiagen). The nuclear rDNA ITS2 was amplified by the polymerase chain reaction (PCR) using the ITS2F and ETTS1 primers (Vidigal et al., 2000) in a $50 \mu \mathrm{L}$ total volume of amplification mixture containing 10-100 ng of Biomphalaria DNA, $0.2 \mathrm{mM}$ of each dNTP, $0.10 \mu \mathrm{m}$ of each primer and $1 \mathrm{U}$ of Taq DNA polymerase (BioLabs) with the supplied buffer. The following PCR temperature profile was used: a initial 4 min denaturation step at $94{ }^{\circ} \mathrm{C}$ followed by 35 iterations of $30 \mathrm{~s}$ at $94{ }^{\circ} \mathrm{C}, 1 \mathrm{~min}$ at $60^{\circ} \mathrm{C}$ and $1 \mathrm{~min}$ at $72{ }^{\circ} \mathrm{C}$ plus a final $7 \mathrm{~min}$ extension at $72^{\circ} \mathrm{C}$. The PCR products were checked by agarose gel electrophoresis, cleaned using QIAquick PCR Purification Kits (Qiagen) and cloned using TOPO TA Cloning (Invitrogen) or pGEM-T (Promega) kits. One recombinant clone was sequenced per individual. Sequencing was carried out at the Human Genome Research Center (CEGH, São Paulo).

Sequences were corrected using the program Chromas (Technelysium Pty Ltd.), aligned using the program ClustalX version 1.8 (Thompson et al., 1997) and the alignments subsequently adjusted by eye using the program BioEdit version 7.0 (Hall, 1999). Two sequence alignments were built: one for the Ourinhos-Ipauçu data set, and another including a number of published sequences, also listed in Table 1. Nucleotide diversity ( $\pi$, Nei, 1987 , equations 10.5 or 10.6 and 10.7) and nucleotide divergence between sequence groups $\left(D_{x y}, N e i, 1987\right.$, equation 10.20 using Jukes and Cantor correction) were calculated using the program DnaSP version 4.1 (Rozas et al., 2003).

The program MrModeltest version 2.0 (Nylander, 2004) was used to determine the best-fit model of DNA sequence evolution and model parameters for the sequence alignments. The data was used to choose the model form for Bayesian inference of phylogeny as implemented in the program MrBayes version 3.1 (Huelsenbeck and Ronquist, 2001). Two simultaneous independent searches were run for $1.5 \times 10^{6}$ generations, with trees saved every 100 generations, and the first 1,500 sampled trees of each search discarded as "burn-in". The data obtained in MrModeltest 2.0 was also used to obtain maximum-likelihood (ML) trees using the program PAUP* version 4.0 (Swofford, 2002), employing the heuristic search option and 100 random taxon addition replicates to improve tree searches. Clade support was assessed by 500 bootstrap pseudo-replicates, again with random addition of taxa (for the Ourinhos-Ipauçu data set only). Additionally, maximum parsimony (MP) trees were obtained using PAUP* 4.0 heuristic search option with 100 random additions, followed by computation of strict consensus trees and 1,000 bootstrap pseudo-replicates with random addition of taxa for measure of support. Gaps were treated as missing data. In all phylogenetic analyses $B$. peregrina was designated the outgroup.

The ITS2 fragments sequenced displayed a length range of 424-449 bp (primers excluded). The final alignment matrix for the 16 sequences $(9 B$. tenagophila, $3 B$. glabrata, 2 B. occidentalis and 2 B. peregrina) consisted of
468 characters, 69 of which were parsimony informative. The best-fit model of sequence evolution suggested by MrModeltest 2.0 for this alignment was the general time reversible (GTR) plus G (gamma distribution for rate variation among sites). The majority rule consensus tree obtained from the convergence of two independent Bayesian runs is shown in Figure 1. Exactly the same topology was observed in the single resulting ML tree $(-\ln L=$ 1094.27). MP searches yielded four equally parsimonious trees of length 87, consistency index $(\mathrm{CI})=0.977$ and retention index $(\mathrm{RI})=0.987$. The strict consensus showed the same topology of the Bayesian/ML trees, except for the clade containing the B. glabrata sequences, which became an unresolved trichotomy.

The tree depicted in Figure 1 shows a close relationship between $B$. tenagophila and $B$. occidentalis, with this grouping being well differentiated from both $B$. glabrata and $B$. peregrina clades. These results are in accordance with previous ITS2 studies using the same species (Vidigal et al., 2000; DeJong et al., 2001; Pointier et al., 2005). It is noteworthy, though, that some differentiation between $B$. tenagophila from the two collection sites was noticeable in the tree.

For comparison with previous studies, 48 Biomphalaria ITS2 sequences were added to the Ourinhos-Ipauçu data set, yielding a sequence alignment of 497 characters, 82 of which were parsimony informative. Identical sequences (in the Ourinhos-Ipauçu data set) and sites 474 to 497 were removed before analyses. Included in the alignment were all $B$. glabrata, B. tenagophila, $B$. occidentalis and B. peregrina ITS2 sequences presented in Vidigal et al. (2000, 2004), DeJong et al. (2001), Mavárez et al. (2002; except AF449580, due to sequence incompleteness) and Pointier et al. (2005). Figure 2 depicts the

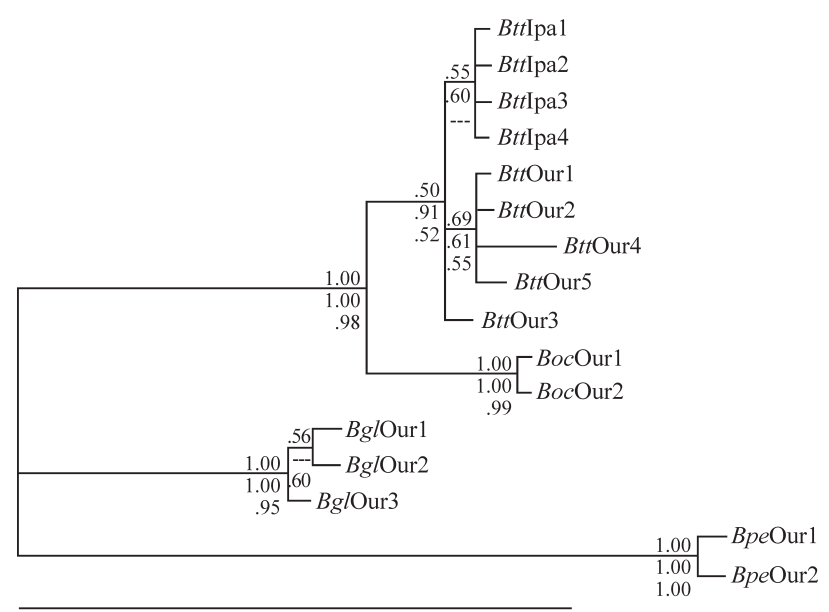

0.1 substitutions/site

Figure 1 - Bayesian majority rule consensus phylogram for the OurinhosIpauçu ITS2 data set. Values above nodes indicate clade posterior probabilities and those below refer to maximum parsimony (MP) and maximum likelihood (ML) bootstrap proportions, respectively (values lower than .50 are not shown). 
Bayesian majority rule consensus tree obtained for this data set, using the parameters form of the GTR + G model, as recommended by MrModeltest 2.0. The ML analysis produced two trees of $-\ln L=1610.16$, differing minimally from one another: tree \# 1 had $B g l \mathrm{BH}$ sister to $B g l$ Est $1 / 2$ and tree \#2 displayed the same topology for the B. glabrata clade as the Bayesian one. Both ML trees also differed from the Bayesian one by a minor variation in the $B$. peregrina clade (BpeBJ sister to BpeTai/BpeSA). Evaluation of clade support for the ML trees via bootstrapping was precluded by computing limitations. The MP analysis yielded an incalculable number of trees of length 160 (CI $=0.863$, $\mathrm{RI}=0.977$ ), but the strict consensus of the first 100,000 retained trees produced the same topology as the Bayesian tree, except that $B g l$ Est 1 and $B g l$ Est 2 did not cluster together. MP bootstrap values (maximum number of trees retained per iteration set to 200) are indicated in Figure 2.

All B. glabrata sequences were recovered in a monophyletic clade, containing a set of defined branches denominated V1, V2 and B in Figure 2. These branches were also characterized by Mavárez et al. (2002), using concatenated ITS2 and mitochondrial 16S rDNA sequences. Venezuela harbors two distinct ITS2 lineages (V1 and V2) and, interestingly, the Venezuelan sample reported in Vidigal et al. (2000) clearly belongs to subgroup V2, showing that this clade is more widespread than previously thought. The Brazilian clade (B), also reported by Mavárez et al. (2002) for two sequences ( $B g l \mathrm{BH}$ and BlgSal 2), contained all other Brazilian sequences published to date (BglSal 1, DeJong et al., 2001; BglEst 1-2, BglBel, Vidigal et al., 2000) except the ones from Ourinhos (BglOur 1-3), these latter sequences appearing in an unstructured, more basal, region of the $B$. glabrata clade, along with the sequences from Central America (BglPie, BglMau, BglGC, $B g l \mathrm{Val}, B g l \mathrm{VF}, B g l \mathrm{RG}, B g l \mathrm{Jar})$.

In contrast to $B$. glabrata, the clade containing $B$. tenagophila, B. t. guaibensis, and B. occidentalis sequences displayed a polyphyletic pattern (the $B$. tenagophila complex, Spatz et al., 1999; Vidigal et al., 2004). The $B$. tenagophila sequences were observed in two different branches (T1 and T2). The two B. occidentalis samples from Argentina (BocTri and BocVC) also appeared on separate branches, one clustered with $B$. $t$. guaibensis sequences $(\mathrm{G} / \mathrm{O})$, the other with the remaining $B$. occidentalis (O). However, unlike in Vidigal et al. (2004), support for joint monophyly of branches $\mathrm{G} / \mathrm{O}$ and $\mathrm{O}$ was not obtained.

Interestingly, sub-structuring within the $B$. tenagophila $\mathrm{T} 1$ branch was observed, extending the differentiation characterized for the Ourinhos/Ipauçu data set to other samples (T1 groups a and b). Additionally, some underived $B$. tenagophila sequences were recovered, in the same fashion of the $B$. glabrata clade. In fact, substructuring within $B$. tenagophila $\mathrm{T} 1$ makes the nucleotide diversity in this branch only $(\pi=0.893 \% \pm 0.232)$ comparable to that found in the entire $B$. glabrata data set

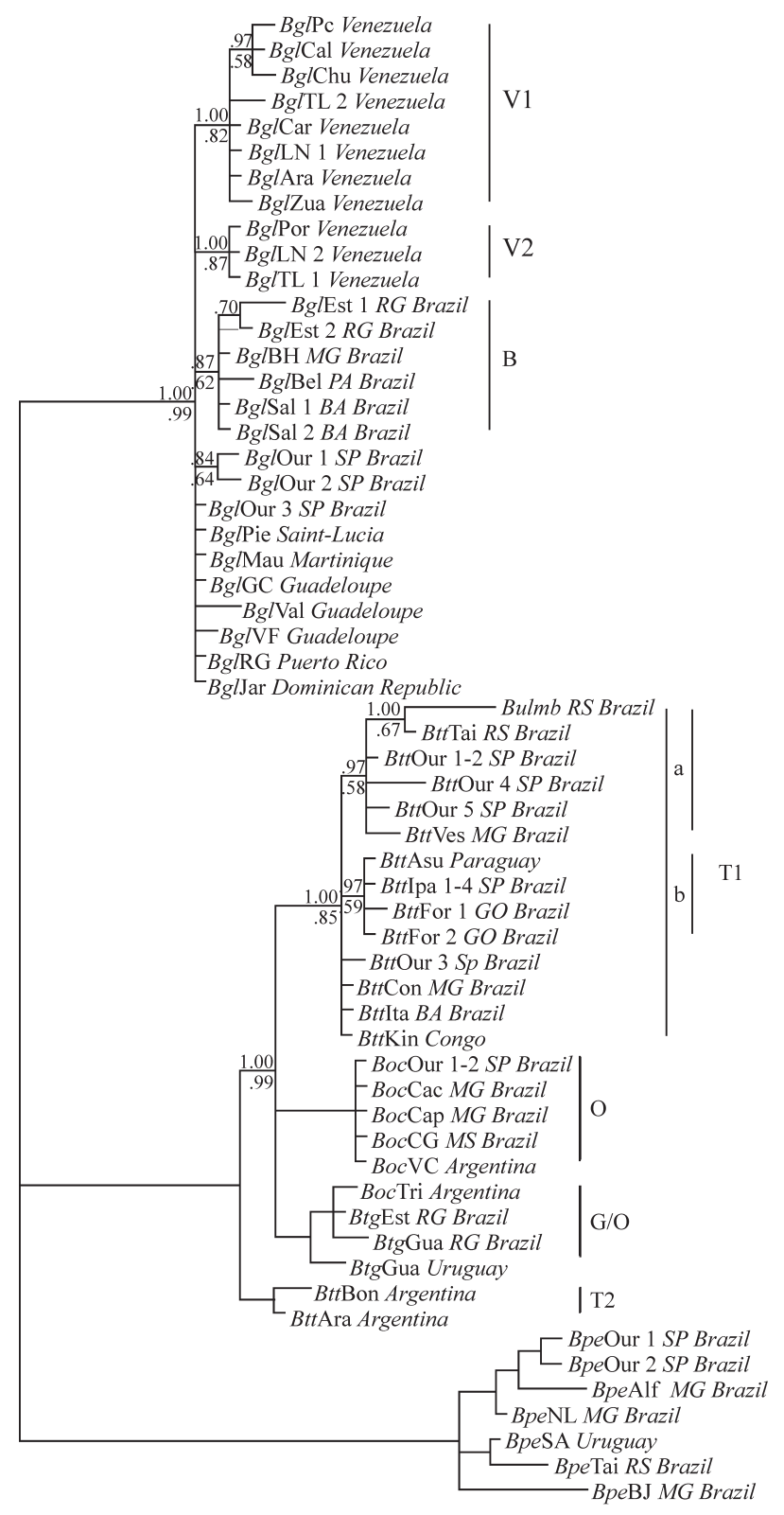

0.1 substitutions/site

Figure 2 - Bayesian phylogenetic tree for Biomphalaria ITS2 sequences. Values above and below nodes indicate clade posterior probabilities and maximum parsimony (MP) bootstrap proportions, respectively.

$(\pi=0.729 \% \pm 0.084)$. Divergence between branches within B. glabrata and B. tenagophila $\mathrm{T} 1$ is also similar (e.g. $\left.\mathrm{D}_{\mathrm{V} 1-\mathrm{V} 2}=1.277 \% \pm 0.338, \mathrm{D}_{\mathrm{T} 1 \mathrm{a}-\mathrm{b}}=1.215 \% \pm 0.434\right)$. However, when the entire $B$. tenagophila complex is considered it becomes apparent that not only is it comprised of highly diverse sequences ( $\pi=1.604 \% \pm 0.176)$ but also that divergence within the nominal $B$. tenagophila is far larger $\left(\mathrm{D}_{\mathrm{T} 1-\mathrm{T} 2}=2.029 \% \pm 0.532\right)$ than within the nominal $B$. glabrata (for which $\mathrm{D}_{\mathrm{V} 1-\mathrm{V} 2}$ gives the highest pairwise value). Finally, the $B$. peregrina clade also encompasses a set of divergent sequences, which is reflected in a remark- 
ably high level of nucleotide diversity $(\pi=1.823 \% \pm$ 0.412 ).

Whereas cross validation with independent biological markers remains a critical step in assessing the nature and significance of ITS2 variability in Biomphalaria, the patterns of genetic differentiation revealed in ITS2 studies nonetheless provide significant information about barriers to gene flow. Thus, it is remarkable to observe fixed differences between $B$. tenagophila samples from Ourinhos and Ipauçu, localities no more than $30 \mathrm{~km}$ apart, and this finding may indicate low connectivity between these sites and deserves further investigation. It is also noteworthy that $B$. glabrata sequences from Ourinhos did not cluster with the remaining samples from Brazil, and in this case additional sampling within São Paulo and other Brazilian states will be needed to elucidate the significance of this finding on a broader phylogeographical scale. Nonetheless, we note that in both cases the low magnitude of change $(\pi<1 \%)$ seems to indicate these are likely to be examples of intraspecific polymorphism. Actually, a cohesive status for $B$. tenagophila $\mathrm{T} 1$ and $B$. glabrata samples is suggested not only by the magnitude, but also by the pattern of distribution of ITS2 variability. The latter is apparent in the structure of both clades, which exhibit a few distinct but short branches and a set of undifferentiated sequences displayed in a "rake" fashion - the typical pattern of continuous sequence variability characteristic of single species (Crandall and Templeton, 1993). We investigated this pattern further by examining statistical parsimony networks obtained with the program TCS (Clement et al., 2000) separately for B. glabrata and B. tenagophila $\mathrm{T} 1$ sequences. In both cases, the most undifferentiated (zero length branches) sequences (BglOur 3, $B g l$ Pie, BglMau, BglGC, BglRG and BglJar for $B$. glabrata, BttCon, BttIta and BttKin for B. tenagophila T1) occupied central (ancestral) positions in the networks, holding most of the mutational connections with other sequences (data not shown). One direct implication of this finding is that, considering the presumably recent introduction of B. tenagophila into Africa (Pointier et al., 2005), ITS2 genotyping would offer limited power for source estimation of the Kinshasa population - the use of multiple and/or more sensitive genetic markers would be required in this case. However, since the reliability of network inferences (in particular the assignment of ancestral sequences) depends on dense populational sampling (Crandall and Templeton, 1993), and is, in general, an inadequate tool for use on data sets obtained mainly for taxonomic studies, these results must be regarded with caution, solely as preliminary conjectures to be tested with additional data.

When the $B$. glabrata clade was compared with the entire $B$. tenagophila complex clade, however, a more intricate picture emerged: vis-à-vis, the $B$. glabrata clade was shallower with less differentiated branches than the $B$. tenagophila complex clade (Figure 2). Here, both the degree and the pattern of differentiation of $B$. tenagophila $\mathrm{T} 1$ and $\mathrm{T} 2$ branches supply compelling evidence that these samples may belong to distinct, yet cryptic, species.

Finally, in our reappraisal of the ITS2 data it was interesting to identify that the highest level of sequence diversity among all the species analyzed was for $B$. peregrina. Historically, species of greater epidemiological importance such as B. glabrata have received more attention in population genetic studies, and their respective levels of genetic diversity, therefore, emphasized (B. glabrata was once called "the most differentiated mollusc species yet described", Woodruff and Mulvey, 1997). However, as data from multi-species studies accumulates it becomes evident that several Neotropical Biomphalaria species (such as $B$. tenagophila and B. peregrina) show remarkably high levels of genetic variability. This is a relevant finding from both epidemiological and evolutionary viewpoints and supports, for instance, the hypothesis of a Neotropical origin for the genus (Campbell et al., 2000; DeJong et al., 2001). Moreover, it highlights the need for further studies aimed at investigating patterns of population structure and species limits for these taxa.

\section{Acknowledgments}

Funding for this work was provided by the Brazilian agency FAPESP (Fundação de Amparo à Pesquisa do Estado de São Paulo), grant 03/00039-2.

\section{References}

Campbell G, Jones CS, Lockyer AE, Hughes S, Brown D, Noble LR and Rollinson D (2000) Molecular evidence supports an african affinity of the neotropical freshwater gastropod, Biomphalaria glabrata, say 1818, an intermediate host for Schistosoma mansoni. Proc Biol Sci 267:2351-8.

Clement M, Posada D and Crandall KA (2000) TCS: A computer program to estimate gene genealogies. Mol Ecol 9:16571659.

Crandall KA and Templeton AR (1993) Empirical tests of some predictions from coalescent theory with applications to intraspecific phylogeny reconstruction. Genetics 134:959969.

DeJong RJ, Morgan JA, Paraense WL, Pointier JP, Amarista M, Ayeh-Kumi PF, Babiker A, Barbosa CS, Bremond P, Pedro Canese A, de Souza CP, Dominguez C, File S, Gutierrez A, Incani RN, Kawano T, Kazibwe F, Kpikpi J, Lwambo NJ, Mimpfoundi R, Njiokou F, Noel Poda J, Sene M, Velasquez LE, Yong M, Adema CM, Hofkin BV, Mkoji GM and Loker ES (2001) Evolutionary relationships and biogeography of Biomphalaria (Gastropoda, Planorbidae) with implications regarding its role as host of the human bloodfluke, Schistosoma mansoni. Mol Biol Evol 18:2225-2239.

Hall TA (1999) BioEdit: A user-friendly biological sequence alignment editor and analysis program for Windows 95/98/NT. Nucl Acids Symp Ser 41:95-98.

Huelsenbeck JP and Ronquist F (2001) MrBayes: Bayesian inference of phylogenetic trees. Bioinformatics 17:754-755. 
Mavárez J, Steiner C, Pointier J-P and Jarne P (2002) Evolutionary history and phylogeography of the schistosome-vector freshwater snail Biomphalaria glabrata based on nuclear and mitochondrial DNA sequences. Heredity 89:266-272.

Nei M (1987) Molecular Evolutionary Genetics. Columbia University Press, New York, 512 pp.

Nylander JAA (2004) MrModeltest 2.0. Program distributed by the author. Evolutionary Biology Centre, Uppsala University.

Paraense WL (2001) The schistosome vectors in the Americas. Mem Inst Oswaldo Cruz 96(Suppl.):7-16.

Pointier J-P, DeJong RJ, Tchuem Tchuenté LA, Kristensen TK and Loker ES (2005) A neotropical snail host of Schistosoma mansoni introduced into Africa and consequences for the schistosomiasis transmission: Biomphalaria tenagophila in Kinshasa (Democratic Republic of Congo). Acta Tropica 93:191-199.

Rozas J, Sanchez-Del Barrio JC, Messeguer X and Rozas R (2003) DnaSP, DNA polymorphism analyses by the coalescent and other methods. Bioinformatics 19:2496-2497.

Spatz L, Vidigal THDA, Caldeira RL, Dias Neto E, Cappa SMG and Carvalho OS (1999) Study of Biomphalaria tenagophila tenagophila, B. t. guaibensis and B. occidentalis by polymerase chain reaction amplification and restriction enzyme digestion of the ribosomal RNA intergenic spacer regions. J Molluscan Stud 65:143-149.

Swofford DL (2002) PAUP*. Phylogenetic Analysis Using Parsimony (*And Other Methods). Version 4. Sinauer Associates, Sunderland.

Thompson JD, Gibson TJ, Plewniak F, Jeanmougin F and Higgins DG (1997) The ClustalX windows interface: Flexible strategies for multiple sequence alignment aided by quality analysis tools. Nucleic Acids Res 25:4876-4882.

Vidigal THDA, Kissinger JC, Caldeira RL, Pires ECR, Monteiro E, Simpson AJG and Carvalho OS (2000) Phylogenetic relationships among Brazilian Biomphalaria species (Mollusca, Planorbidae) based upon analysis of ribosomal ITS2 sequences. Parasitology 121:611-620.

Vidigal TH, Spatz L, Kissinger JC, Redondo RA, Pires EC, Simpson AJ and Carvalho OS (2004) Analysis of the first and second internal transcribed spacer sequences of the ribosomal DNA in Biomphalaria tenagophila complex (Mollusca, Planorbidae). Mem Inst Oswaldo Cruz 99:153158.

Woodruff DS and Mulvey M (1997) Neotropical schistosomiasis: African affinities of the host snail Biomphalaria glabrata (Gastropoda: Planorbidae). Biol J Linn Soc 60:505-516.

Associate Editor: Fábio de Melo Sene 